\title{
Therapeutic Education and Physiotherapy in Low Back Pain Management
}

\author{
Stilyana Romanova ${ }^{1,2}$, Kristin Grigorova ${ }^{1}$, Antoaneta Dimitrova ${ }^{1 *}$ (D) \\ ${ }^{1}$ Department of Physiotherapy and Rehabilitation, National Sports Academy "Vassil Levski", Sofia, Bulgaria; ${ }^{2}$ Rehabilitation \\ Center "Physio-Health Sofia", Sofia, Bulgaria
}

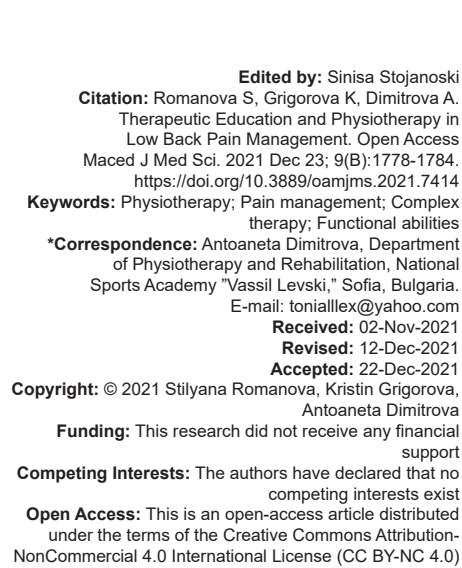

\section{Introduction}

Low-back pain (LBP) is a very common health problem worldwide [1]. The prevalence of nonspecific LBP in all age groups is very high and is estimated to be $60-70 \%$ in industrialized countries [2]. Supporting this statement, the new studies show that only $8-15 \%$ of LBP can be defined as specific, which suggests that the structural degenerations are not causing the pain in most of the cases [3]. Despite this data, pathoanatomical degenerations are still considered the first line in back pain diagnosis, and the term "non-specific pain" is not widely used.

There are many treatment options in chronic LBP including surgical and non-surgical treatment. The conservative approaches include pharmacological and non-pharmacological treatment, often used in combination. Of non-pharmacological type of treatment, the physiotherapy (PT) is an essential part of complex therapy for improving functionality and preventing disability.

The classical medical approach can hinder adequate treatment if it focuses only on the exclusion of serious health issues, especially in patients that may mainly need an understanding of their problems and pain relief. Frequently, the type of information presented to a patient with LBP is based on a medical model and the emphasis is on structural pathologies and biomechanics at the expense of the cognitive aspects of an individual's pain experience [4], [5]. This type of information is not conducive to the necessary psychological change and at the same time can lead to iatrogenic consequences for patients with chronic pain and increased health care consumption [4]. The patient's attitude and level of health knowledge pose a significant problem for the effective treatment of LBP. Simultaneously, the use of analgesics, which according to some authors can be described as an opioid epidemic needs to be reduced [6].

Modern guidelines to treat LBP are targeted at identifying the three main domains influencing the symptoms - biological, psychological, and social. The biological domain includes features such as tissue pathology, motor control problems, central and peripheral sensitization, immune system responses, changes in brain structure and behavior. The psychological influence is expressed by pain coping, 
pain catastrophization, kinesiophobia, depression, anxiety, distress, pain behavior and these have different implications for the treatment. The social domain includes the possibility of working, satisfaction, and social support [7].

Therapeutic patient education is a method that enables health care professionals to pass on their knowledge and experience to patients so that they can participate consciously and actively in their recovery [8]. TE addresses the problems by emphasizing the patientoriented approach and the heterogeneous nature of pain. Patient education is also defined as a planned learning experience, implementing a combination of methods such as teaching, counseling, and behavior techniques, to improve their quality of life [9]. It is considered an integral component of effective patient care and an important element to meeting future health care needs [9]. Several guidelines and systematic reviews recommend TE based on neurophysiological pain education (NPE) as an effective part of the complex therapy in chronic LBP management [3], [10], [11], [12]. In patients with acute LBP, international guidelines also recommend TE to reduce patients' fears and negative beliefs and to promote active recovery [1]. Recent research shows that patients also seek information about their problems and expect that education will enable them to take control of their condition [9]. According to a systematic review, patients are looking for clear, consistent, and personalized information on diagnosis, prognosis, and treatment options, including pharmacological and non-pharmacological strategies. Patients also want the information to be delivered in an understandable language and counseling and treatment to be individualized, tailored to their lifestyle, age, and social status [13]. All this data indicates a gap in the management of LBP and the use of available information in clinical practice.

\section{Aim}

The present study aims to examine the feasibility and the effect of TE, combined with specific $\mathrm{PT}$ in people with non-specific chronic LBP.

\section{Materials and Methods}

\section{Participants}

The study involved 25 patients (mean age $43.08 \pm 12$ years, 12 women) with non-specific chronic LBP (mean duration in months $20.2 \pm 29.6$ ). Patients were recruited in a single medical center in Sofia, Bulgaria for 3 months and randomly divided into two groups according to the capital letter of their family names: experimental group (EG), including TE $(n=18)$, and control group (CG), without TE $(n=7)$. Inclusion criteria are: the presence of chronic non-specific LBP ( $\geq 12$ weeks), age between 20 and 60 years, and be independent in daily activities. The exclusion criteria: history of spinal operation, pregnancy, red flags disorders (like fractures or infections, cancer, cauda equina syndrome), unstable cardiac conditions, central nervous system diseases (multiple sclerosis, Parkinson's disease, stroke), cognitive disorders, severe rheumatological disease.

\section{Measurements}

Demographic data in both groups was recorded (age, sex) and information about medical history and previous treatment. Assessments of outcomes were taken at the beginning and one month later - at the end of the intervention. The primary outcomes variables were LBP prognostic indicators measured by StarRt Back Screening Tools and movement-induced pain in the lumbar spine [14], [15]. Secondary outcomes measures were disabilities in daily life measured by Oswestry Disability Index (ODI) and fear of movement by Tampa Scale for Kinesiophobia [16], [17].

\section{Intervention}

The treatment frequency and duration were consistent in the two groups. Depending on the symptoms, from one to six under supervision - faceto-face sessions for EG and 2-6 sessions for CG, were performed. All patients were instructed to perform specific exercises at home until the next visit or until the impaired functions were restored. Individual selections of the appropriate physiotherapeutic interventions were made after functional examination and the mechanical response from movement-induced pain in the lumbar spine. The patient-centered approach was followed according to type of pain, and the applied PT interventions are presented in Figure 1. The PT included mobilizations with movements by Mulligan, Mechanical Diagnosis and Therapy (MDT) and neuro mobilization. At the beginning of the treatment, patients were classified according to their pain characteristics (nociceptive, neuro disorder, central sensitization). For those patients with nociceptive pain, referred from nonneural structures such as the disc or facet joints, the treatment program consisted of mobilization by Mulligan and MDT. Patients with neuro disorder, classified as peripheral nerve sensitization were treated with neuro mobilization. The patients with compressive neuropathy, were treated with MDT and neuro mobilization. For patients with Central sensitization, characterized by an increase of neural signaling within the central nervous system that elicits pain hypersensitivity, cognitive functional therapy (CFT) was applied.

The patients in the $E G$ also received $T E$, based on an NPE and CFT, as a part of the complex intervention. 


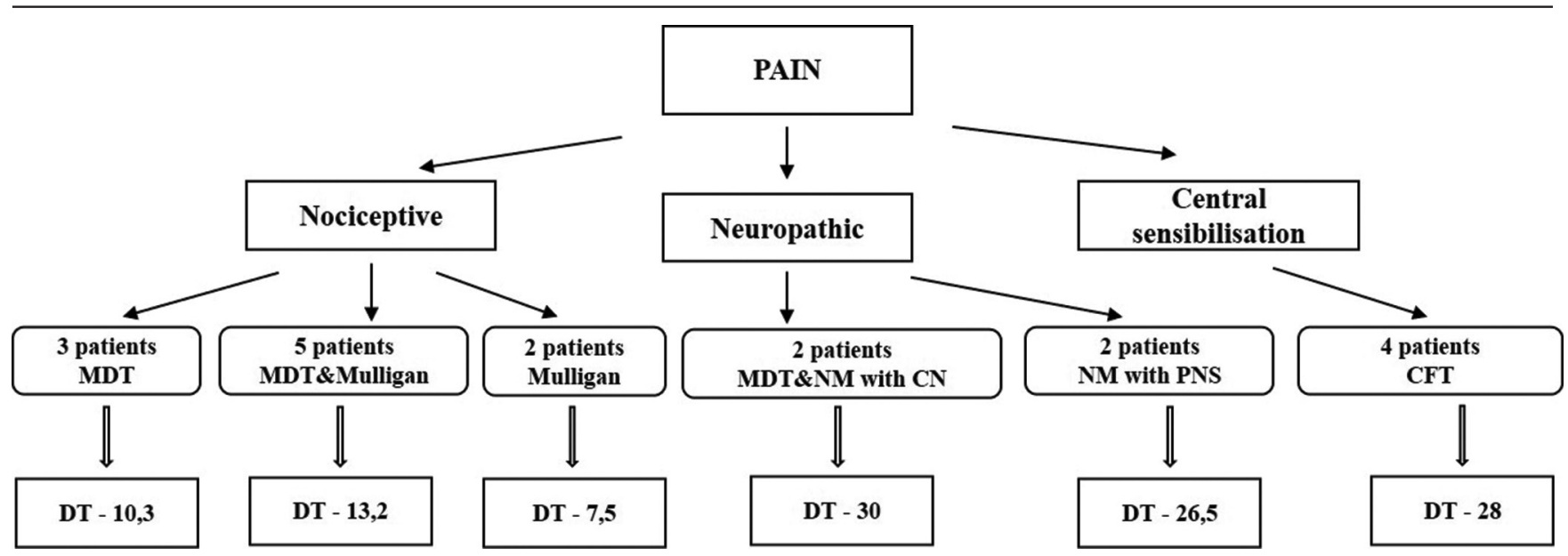

Figure 1: Distribution of the patients in the experimental group according to the applied therapy. DT: Average days of therapy, NM: Neuro Mobilizations, MDT: Mechanical Diagnosis and Therapy, CN: Compressive neuropathy, PNS: Peripheral nerve sensitization, CFT: Cognitive Functional Therapy

NPE is a cognitive functional intervention that aims to change the misunderstanding and maladaptive behavior to influence pain and disability in patients with back pain [18]. The aim is to reconceptualize pain as a protective mechanism of the brain, rather than tissue damages. Education is a conceptual framework based on the neurobiological processes for the mechanism of pain but explained in an understandable language for patients. It integrates the various cognitive, social, and contextual factors that modulate pain and uses the basis of the bio-psycho-social model for managing the problem [1].

Cognitive-functional therapy as a modern patient-centered behavioral intervention incorporates a bio-psycho-social approach to managing LBP [19]. It uses a multidimensional clinical reasoning framework and emphasizes the role of the physical, social, mental, and behavioral aspects of LBP [20]. The cognitive component of CFT involves dealing with negative beliefs, fear of movement, and pathoanatomical abnormalities in imaging, as well as education about the mechanism of pain and awareness of the body-mind responses to pain, movement, and their perceived threat. The functional component of CFT is behaviorally directed and involves retraining body schema, normalizing provocative movement patterns, and influencing the patient's functional goals [21]. This approach was applied to achieve a long-lasting effect while observing the main learning principles. The structuring was created based on the following stages:

Cognitive stage - more verbal and visual information was used, aimed at introducing NPE to consciously change the patient's attitude toward the nature of the problem. A patient information leaflet has been compiled explaining in accessible language the mechanism of pain

- Associative stage - cognitive behavioral education and training of painless movements and activities to adapt the nervous system and improve functional abilities and performance - $\quad$ Autonomous stage - strategies to control the pain and lifestyle changes to achieve a lasting effect.

\section{Statistical analysis}

The analysis of the data gathered was carried out with the Statistical Package for the Social Sciences version 19.0. Descriptive statistics (mean and standard deviation), a Wilcoxon test for paired and unpaired samples to determine the significance of changes in outcome measures were used. The significance was set up at $p \leq 0.05$.

\section{Results}

The impact of pain during movement is presented in Table 1. It is noteworthy that most patients had moderate pain during flexion and also moderate pain during extension. At the end of the follow-up period,

Table 1: Distribution of the patients from both groups according to the movement-induced pain

\begin{tabular}{|c|c|c|c|c|c|}
\hline \multirow[t]{2}{*}{ Direction } & \multirow[t]{2}{*}{ Pain intensity } & \multicolumn{2}{|c|}{$E G(n=18)$} & \multicolumn{2}{|c|}{ CG $(n=7)$} \\
\hline & & Start $(n)$ & End (n) & Start (n) & End (n) \\
\hline \multirow[t]{4}{*}{ Flexion } & Nil & 2 & 15 & - & 3 \\
\hline & Minimal & 1 & 1 & 1 & 3 \\
\hline & Mood & 12 & - & 5 & 3 \\
\hline & Major & 3 & - & 1 & - \\
\hline \multirow[t]{4}{*}{ Extension } & Nil & 6 & 12 & - & 3 \\
\hline & Minimal & - & 4 & 1 & 2 \\
\hline & Mood & 9 & - & 3 & 2 \\
\hline & Major & 3 & - & 3 & - \\
\hline \multirow[t]{4}{*}{ LF-L } & Nil & 9 & 15 & 6 & 7 \\
\hline & Minimal & 2 & 1 & 1 & - \\
\hline & Mood & 6 & - & - & - \\
\hline & Major & 1 & - & - & - \\
\hline \multirow[t]{4}{*}{ LF-R } & Nil & 11 & 16 & 5 & 7 \\
\hline & Minimal & 3 & - & 1 & - \\
\hline & Mood & 2 & - & 1 & - \\
\hline & Major & 2 & - & - & - \\
\hline
\end{tabular}


a decrease in the intensity of pain was reported in both groups, but in the EG a larger number of patients fell into the group with no pain during certain movements (flexion and extension).

The frequency distribution of the patients by categories, according to the degree of the functional disability by ODI is presented in Figure 2.

The most of the patients from both groups initially falls into the category of moderate disability. At the end of the follow-up period, there are no patients with severe disability and there is an increase in the number of patients in the category of minimal disability (93.8\% of patients are in this category for EG and $71.4 \%$ of $\mathrm{CG})$.

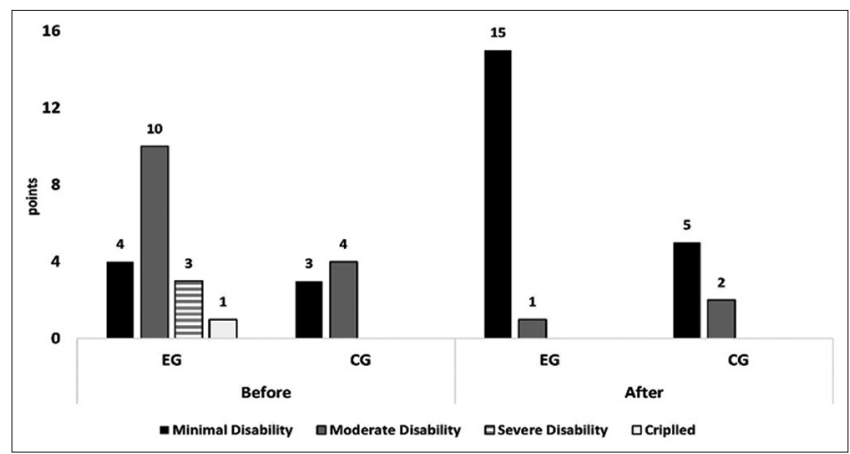

Figure 2: Changes in the disability's level in mean points during treatment. EG: Experimental group, CG: Control group, $n$ : Number of the patients

Table 2 presents the average number of points at the beginning and the end of the study. The mean values of the outcome results for both groups are above the cut-off score of 37 points, which is considered a sign of the presence of protective behavior (Vlayen et al., 1990).

Table 2: Changes in the mean values of the Tampa Scale for Kinesiophobia during the treatment

\begin{tabular}{|c|c|c|c|}
\hline \multirow{2}{*}{ Groups } & EG $(n=18) ; C G(n=7)$ & $E G(n=16) ; C G(n=7)$ & \multirow{2}{*}{ Difference } \\
\hline & $\mathrm{X}_{1} \pm \mathrm{sd}_{1}$ & $\mathrm{X}_{2} \pm \mathrm{sd}_{2}$ & \\
\hline EG & $45.2 \pm 7.7$ & $33.2 \pm 3.3^{\star \star \star}$ & $12.3 \pm 5.1$ \\
\hline CG & $42.3 \pm 7.8$ & $38.7 \pm 6.3^{\star}$ & $3.6 \pm 3.8$ \\
\hline $\mathrm{p}$ & 0.412 & 0.065 & 0.001 \\
\hline
\end{tabular}

At the end of the follow-up period, a decrease in the total score was reported, with a difference of 12.3 points for EG and 3.6 points for CG. In both groups, there is a decrease in the result, but only in the EG, the last points are below the cut-off score of 37 points.

\section{Discussion}

The results of the study showed that the TE in combination with specific PT could help reduce pain during daily movement activities. We attribute the better subjective perceptions of EG regarding the fear of moving to the role of applied NPE and CFT. A similar effect was reported in a randomized controlled trial, which confirmed the role of NPE in patients with chronic LBP, reporting improved pain cognitions and physical performance by SLR test and forward bending [4]. Two randomized controlled trials have emphasized the effect of CFT in reducing pain intensity, negative beliefs, and fear of movement, compared to traditional manual therapy and exercises [22], [23]. Biomechanical and anatomical models are used in traditional PT education to explain to patients the nature of the problem. Furthermore, these models of explanation have been associated with increased fear, anxiety, and faulty beliefs among some patients [24]. At the same time, this approach may have limited effectiveness in patients with chronic pain due to their inability to understand the nature of persistent pain. It is suggested that these traditional models may be the cause of insufficient efficacy in the treatment of back pain and increase the risk of mental iatrogenic consequences for the patients. The patients with LBP often have biomechanical model beliefs that their pain is associated with tissue damages, although current research has shown that changes in imaging do not correlate with pain symptoms but are rather a part of normal degeneration of the body [18], [25]. According to Louw et al. (2016), it is necessary to consider what instructions we give to patients at the initial phase of injury and how they affect subsequent recovery [26].

In our opinion, the correct explanation of the nature of the problem has a significant impact on preventing anxiety among patients. The results of the study regarding the assessment of ODI show a tendency for better subjective functional disability for EG compared to the CG. In the systematic review of Marris et al. (2019) it's confirmed that NPE in combination with PT leads to reduction of the pain symptoms and improves the functional abilities of patients [12]. When working with patients with pain, physiotherapists should consider that psychological factors, both cognitive and emotional, may influence pain symptoms, as well as perception and disability [20]. These factors are best manifested in patients with chronic pain and according to Tegner et al. (2018) psychological domains have a higher impact on the intensity of pain than the medical imaging results [3].

Our results confirm other authors' conclusions that CFT leads to a significant decrease in the intensity of pain, disability and improve the quality of life in patients with LBP [27]. The integrative patient-centered approach, which includes TE and active patient participation, has been recommended with a high level of evidence by several international guidelines for the management of LBP [8]. According to Traeger et al. (2019), the first step of LBP management should include advice and education on the mechanism of pain, which calm the patients. As a second step, the use of various therapeutic interventions, such as manipulation, mobilization, exercises, or 
multidisciplinary rehabilitation is recommended [28]. Different therapeutic modalities are aimed at pain management in LBP. Janura et al. (2015) recommended hippotherapy combined with $\mathrm{PT}$ to reduce pain in 13 subjects, average age $42.6 \pm 13.12$ years [29]. Pappas et al. (2013) concluded that Pilates exercise program with fit ball for six weeks reduced pain, compared to standard exercise therapy [30].

Better results for the EG show that following the principles of international guidelines leads to positive changes in functional disability in patients with LBP. We believe that education is a key factor for both patients at higher risk of developing persistent pain and those with low risk too. The subjective feeling of functional independence is associated not only with the reduction of pain symptoms and structural impact on certain segments but also with the ability to control pain in daily activities. From the present study results, we can emphasize the need for a holistic approach that encompasses the social and psychological features of pathology to understand its nature and to influence the complex consequences.

We also consider the positive impact on the therapeutic program in the EG, which followed the basic principles of motor learning. Motor learning requires focusing on the patient's cognitive development rather than the strictly technical performance of a movement. This focus on cognitive development should lead to a long-term change in a patient's movement pattern [31]. NPE that follows the principles of motor skill training leads to changes in cortical excitability and reorganization of the cerebral cortex and is considered an appropriate approach in patients with chronic musculoskeletal pain [32]. The data from our study shows that TE, which follows the principles of NPE, CFT, and motor learning, in combination with specialized exercises and manual therapy leads to better results in terms of subjective perception of the patients' functional abilities and independence with non-specific LBP. The results comply with modern guidelines from the last years, which give priority to the non-medical approaches for the management of LBP [28]. These guidelines are also recommended by the World Health Organization, emphasizing that the use of multiple interventions such as medical imaging, pain medication, steroid injection, and spinal surgery, should be used reasonably, as they may have an opposite effect and lead to more damages for most patients with LBP. Other authors also suggest non-medical approaches and therapeutic modalities to alleviate the patients' condition like hydrokinesitherapy, and video games which meet all the principles of motor learning as active participation by the user, the possibility of frequent and prolonged application, purposefulness and variability of performance [33], [34], [35].

The movement-induced pain was used predominantly in the present study as diagnostic criteria for pain classification to determine the type of therapy. This type of examination was mainly used to determine the mechanism of pain, which can be represented as compression syndrome (associated with pain during extension of the low back while in a stationary standing position) and stretch syndrome (associated with pain during stretch movements).

The presented method in patients with nociceptive pain used the MDT approach, strictly determined by movement-induced pain. It is especially important to refine the therapy, not only about structural changes, but also about the type of mechanical response. Our choice for the use of MDT in the monitored patients is supported by other authors who have studied specific techniques according to these types of symptoms. A similar effect of this approach was established not only in patients with acute pain but also in those with chronic LBP [36], [37].

In the present study, neuro-dynamics techniques were used in patients with neuro-disorders. This choice is supported by other studies which show that neuro mobilization improves flexibility of the sciatic nerve, which reduces the mechanical sensitivity of the nervous system and affects pain [38].

There may be some possible limitations in this study. The first is that the study contingent was not homogeneous in terms of age and duration of the chronicity. It is important to emphasize that the followed patients were predominantly with moderate and minimal functional deficits, and it would be of interest for future study to monitor patients with greater functional limitations. The second limitation concerns that patients with central pain and those with higher limitations need to be treated and followed up for a longer period of time. The study did not consider the possible influence of some contextual factors such as body mass index, educational level, social status and co-morbidities, which would provide additional information on the impact of the combination of specialized approaches and therapeutic education (TE) in these patients.

\section{Conclusion}

TE including NPE and CFT in combination with specialized PT is more effective in improving independence and disability reported through ODI. In addition, the applied education reduced kinesiophobia and lead to more independence in performing daily activities by controlling protective behavior. Future research that focuses on the heterogeneous nature of the pain and at the same time focuses individually on the patient to promote their active recovery is needed. 


\section{Consent to Participate}

All patients written informed consent was obtained.

\section{Human and Animal Rights}

No animals were used in this study. All human procedures were followed in accordance with the principles of the Declaration of Helsinki.

\section{Acknowledgment}

We would like to thank all patients who participated in this study.

\section{Author Contributions}

S.R., K.G-P., A.D. conceived of the presented idea and planned the experiments and contributed information from literature search.

S.R. and A.D. carried out the experiment and data collection.

K.G-P. did the data analysis and supervised the experiments.

All authors have made significant contributions to this manuscript and have approved the final version to be submitted.

\section{References}

1. Traeger A, Moseley G, Hübscher M, Lee H, Skinner IW, Nicholas MK, et al. Pain education to prevent chronic low back pain: A study protocol for a randomised controlled trial. BMJ Openn. 2014;4(6):e005505. https://doi.org/10.1136/ bmjopen-2014-005505

PMid:24889854

2. Balague F, Troussier B, Salminen J. Non-specific low back pain in children and adolescents: Risk factors. Eur Spine J. 1999;8:429-38. https://doi.org/10.1007/s005860050201 PMid:10664299

3. Tegner H, Frederiksen P, Esbensen B, Juhl C. Neurophysiological pain education for patients with chronic low back pain. Clin J Pain. 2018:34(8):778-86. https://doi.org/10.1097/ AJP.0000000000000594

\section{PMid:29443723}

4. Moseley G, Nicholas M, Hodges P. A randomized controlled trial of intensive neurophysiology education in chronic low back pain. Clin J Pain. 2004;20(5):324-30. https://doi. org/10.1097/00002508-200409000-00007 PMid:15322439

5. Louw A, Nijs J, Puentedura E. A clinical perspective on a pain neuroscience education approach to manual therapy. $J$ Manual Manipulat Ther. 2017;25(3):160-8. https://doi.org/10.1080/1066 9817.2017.1323699

PMid:28694679

6. Louw A, Farrell, Choffin B, Foster B, Lunde G, Snodgrass M, et al. Immediate effect of pain neuroscience education for recent onset low back pain: An exploratory single arm trial. J Manual Manipulative Ther. 2019;27(5):267-76. https://doi.org/10.1080/1 0669817.2019.1624006

PMid:31161919

7. Hodges P. Hybrid approach to treatment tailoring for low back pain: A proposed model of care. J Orthop Sports Phys Ther. 2019;49:453-63. https://doi.org/10.2519/jospt.2019.8774 PMid:30759355

8. Vargas-Schaffer G, Cogan J. Patient therapeutic education: Placing the patient at the centre of the $\mathrm{WHO}$ analgesic ladder. Can Fam Physician. 2014;60(3):235-41.

PMid:24627377

9. Forbes R. Patient Education Best Practice; Enhancing Physiotherapy Students' Self-efficacy and Skills. Australia: PhD Thesis, School of Health and Rehabilitation Sciences, The University of Queensland; 2017. https://doi.org/10.14264/ uql.2018.93

10. Stochkendahl M, Kjaer P, Hartvigsen J, Kongsted A, Aaboe J, Andersen $\mathrm{M}$, et al. National clinical guidelines for non-surgical treatment of patients with recent onset low back pain or lumbar radiculopathy. Eur Spine J. 2018;27(1):60-75. https://doi. org/10.1007/s00586-017-5099-2

PMid:28429142

11. Malfliet A, Ickmans K, Huysmans E, Coppieters I, Willaert W Van Bogaert W, et al. Best evidence rehabilitation for chronic pain part 3: Low back pain. J Clin Med. 2019;8(7):1063. https:// doi.org/10.3390/jcm8071063

PMid:31331087

12. Marris D, Theophanous K, Cabezon P, Dunlap Z, Donaldson M The impact of combining pain education strategies with physical therapy interventions for patients with chronic pain: A systematic review and meta-analysis of randomized controlled trials. Physiother Theory Pract. 2019;37(4):461-72. https://doi.org/10.1080/09593985.2019.1633714 PMid:31250682

13. Lim $\mathrm{Y}$, Chou L, Au R, Seneviwickrama KM, Cicuttini FM Briggs AM, et al. People with low back pain want clear, consistent and personalised information on prognosis, treatment options and self-management strategies: A systematic review. J Physiother. 2019;65(3):124-35. https://doi.org/10.1016/j.jphys.2019.05.010 PMid:31227280

14. Rabey M, Beales D, Slater H, O'Sullivan P. Multidimensional pain profiles in four cases of chronic non-specific axial low back pain: An examination of the limitations of contemporary classification systems. Manual Ther. 2015;20(1):138-47. https:// doi.org/10.1016/j.math.2014.07.015 PMid:25153893

15. Chorti A, Chortis A, Strimpakos N, McCarthy CJ, Lamb SE. The prognostic value of symptom responses in the conservative management of spinal pain. Spine. 2009;34(24):2686-99.

16. Fairbank J, Pynsent P. The oswestry disability index. Spine. 2000;25(22):2940-52. https://doi. 
org/10.1097/00007632-200011150-00017

\section{PMid:11074683}

17. Vlaeyen J, Kole-Snijders A, Boeren R, van Eek H. Fear of movement/(re)injury in chronic low back pain and its relation to behavioral performance. Pain. 1995;62(3):363-72. https://doi. org/10.1016/0304-3959(94)00279-N

PMid:8657437

18. King R, Robinson V, Elliott-Button H, Watson JA, Ryan CG Martin DJ. Pain reconceptualisation after pain neurophysiology education in adults with chronic low back pain: A qualitative study. Pain Res Manage. 2018;12:3745651. https://doi. org/10.1155/2018/3745651

PMid:30275918

19. O'Keeffe M, Purtill H, Kennedy N, O'Sullivan P, Dankaerts W, Tighe $A$, et al. Individualised cognitive functional therapy compared with a combined exercise and pain education class for patients with non-specific chronic low back pain: study protocol for a multicentre randomised controlled trial. BMJ Open. 2015;5(6):e007156. https://doi.org/10.1136/ bmjopen-2014-007156

PMid:26033941

20. O'Sullivan P, Caneiro J, O'Keeffe M, Smith A, Dankaerts W, Fersum $\mathrm{K}$, et al. Cognitive functional therapy: an integrated behavioral approach for the targeted management of disabling low back pain. Phys Ther. 2018;98(5):408-23. https://doi. org/10.1093/ptj/pzy022

PMid:29669082

21. Cañeiro J, Nig L, Burnett $A$, Campbell A, O'Sullivan PB. Cognitive functional therapy for the management of low back pain in an adolescent male rower: A case report. J Orthop Sports Phys Ther. 2013;43(8):542-54. https://doi.org/10.2519/ jospt.2013.4699

PMid:23760295

22. Vibe Fersum K, O'Sullivan $P$, Skouen J, Smith A, Kvåle A Efficacy of classification-based cognitive functional therapy in patients with non-specific chronic low back pain: A randomized controlled trial. Eur J Pain. 2013;17(6):916-28. https://doi. org/10.1002/j.1532-2149.2012.00252.x PMid:23208945

23. Vibe Fersum K, Smith A, Kvåle A, Skouen JS, O'Sullivan P. Cognitive functional therapy in patients with non-specific chronic low back pain-a randomized controlled trial 3-year follow-up. Eur J Pain. 2019;23(8):1416-24. https://doi.org/10.1002/ejp.1399 PMid:30974479

24. Louw A, Zimney K, Puentedura E, Diener I. The efficacy of pain neuroscience education on musculoskeletal pain: A systematic review of the literature. Physiother Theory Pract. 2016;32(5):332-55. https://doi.org/10.1080/09593985.201 6.1194646

PMid:27351541

25. Brinjikji W, Luetmer P, Comstock B, Bresnahan BW, Chen LE, Deyo RA, et al. Systematic literature review of imaging features of spinal degeneration in asymptomatic populations. Am J Neuroradiol. 2015;36(4):811-6. https://doi.org/10.3174/ajnr. A4173

PMid:25430861

26. Louw A, Zimney K, O'Hotto C, Hilton S. The clinical application of teaching people about pain. Physiother Theory Pract.
2016;32(5):385-95.

https://doi.org/10.1080/09593985. 2016.1194652

PMid:27351903

27. Vaegter H, Ussing K, Johansen J, Stegemejer I, Palsson TS, O'Sullivan P, et al. Improvements in clinical pain and experimental pain sensitivity after cognitive functional therapy in patients with severe persistent low back pain. Pain Rep. 2020;5(1):e802. https://doi.org/10.1097/PR9.0000000000000802 PMid:32072097

28. Traeger A, Buchbinder R, Elshaug A, Croft PR, Maher CG. Care for low back pain: Can health systems deliver? Bull World Health Organ. 2019;97(6):423. https://doi.org/10.2471/BLT.18.226050 PMid:31210680

29. Janura M, Gallo J, Svoboda Z, Švidernochová D, Kristiníková J. Effect of physiotherapy and hippotherapy on kinematics of lower limbs during walking in patients with chronic low back pain: A pilot study. J Phys Educ Sport. 2015;15(4):663-670. https:// doi.org/10.7752/jpes.2015.04101

30. Pappas E, Panou H, Souglis A. The effect of a pilates exercise programme using fitball on people suffering from chronic lowback pain in terms of pain reduction and function imrovement. J Phys Educ Sport. 2013;13(4):606-11. https://doi.org/10.7752/ jpes.2013.04095

31. Stevans J, Hall K. Motor skill acquisition strategies for rehabilitation of low back pain. J Orthop Sports Physical Therapy. 1998;28(3):165-7. https://doi.org/10.2519/jospt.1998.28.3.165 PMid:9742473

32. Nijs J, Meeus M, Cagnie B, Roussel NA, Dolphens M, Van Oosterwijck $\mathrm{J}$, et al. A modern neuroscience approach to chronic spinal pain: Combining pain neuroscience education with cognition-targeted motor control training. Phys Ther. 2014;94(5):730-8. https://doi.org/10.2522/ptj.20130258 PMid:24481595

33. Lyubenova $\mathrm{D}$, Lyubenov $\mathrm{N}$. Optimizing video games in neurorehabilitation. Neurosonol Cerebral Hemodynamics. 2021;17(2):93-105.

34. Lubenova D. Influence of hydrokinesitherapy in the treatment of lumbar disc disease in the chronic period. Congress Proceedings. Sport Stress Adapt Sci J. 2014;1:629-32.

35. Lubenova D, Izov N, Maznev I. Neurorehabilitation in peripheral nervous system injuries. In: Tityanova EK, editor. Textbook of Nervous Diseases, Clinical Neurology. $1^{\text {st }}$ ed. United States: Saunders; 2021. p. 521-9.

36. Lam O, Strenger D, Chan-Fee M, Pham PT, Preuss RA, Robbins SM, et al. Effectiveness of the McKenzie method of mechanical diagnosis and therapy for treating low Back Pain: Literature review with meta-analysis. J Orthop Sports Phys Ther. 2018;48(6):476-90. https://doi.org/10.2519/jospt.2018.7562 PMid:29602304

37. Sanchis-Sánchez E, Lluch-Girbés E, Guillart-Castells $P$, Georgieva S, García-Molina P, Blasco JM, et al. Effectiveness of mechanical diagnosis and therapy in patients with non-specific chronic low back pain: a literature review with meta-analysis. Braz J Phys Ther. 2020;25(2):117-34. https://doi.org/10.1016/j. bjpt.2020.07.007

PMid:32773288

38. Salem F, Alatawi F. Effectiveness of neural mobilization in the management of chronic low back pain with radiculopathy: A randomized controlled trial. Int J Physiother. 2019;6(5)217-223. 